\title{
Use of Porcine-derived Block Bone Substitutes for Guided Bone Regeneration in the Peri-implant Dehiscence Defects of the Mandibular Anterior Region
}

\author{
Jae-Hong Lee, DDS, MSD, Ph.D ${ }^{1 *}$, Seong-Nyum Jeong, DDS, MSD, Ph.D² \\ ${ }^{1}$ Associate professor, Department of Periodontology, Daejeon Dental Hospital, Institute of Wonkwang Dental \\ Research, Wonkwang University College of Dentistry, Daejeon, Korea \\ 2Professor, Department of Periodontology, Daejeon Dental Hospital, Institute of Wonkwang Dental Research, \\ Wonkwang University College of Dentistry, Daejeon, Korea \\ *Corresponding author: Jae-Hong Lee, Department of Periodontology, Daejeon Dental Hospital, Wonkwang \\ University College of Dentistry, 77 Dunsan-ro, Seo-gu, Daejeon 35233, Korea \\ Tel : +82-42-366-1114. Fax : +82-42-366-1115. E-mail : ljaehong@gmail.com
}

\section{OPEN ACCESS}

pISSN 2765-7833

eISSN 2765-7841

Journal of implantology and applied sciences 2021; 25(4): 170-178

https://doi.org/10.32542/implantology.2021018

Received: September 6, 2021

Revised: December 13, 2021

Accepted: December 13, 2021

ORCID

Jae-Hong Lee

http://orcid.org/0000-0002-2375-0141

Seoung-Nyum Jeong

http://orcid.org/0000-0003-4890-989X

\section{Conflicts of Interest}

The authors declare that they have no competing interests.

Copyright $\odot$ 2021. The Korean Academy of Oral \& Maxillofacial Implantology

This is an Open Access article distributed under the terms of the Creative Commons Attribution Non-Commercial License (http://creativecommons. org/licenses/by-nc/4.0/) which permits unrestricted non-commercial use, distribution, and reproduction in any medium, provided the original work is properly cited.

\section{Abstract}

Purpose: Various bone graft materials are currently used for guided bone regeneration (GBR), but data are lacking on the superiority of one biomaterial relative to the other. In addition, achieving successful bone augmentation remains challenging. When used in GBR, block bone substitutes show better augmentation stability of the bone than particulated bone substitutes. Recently developed softtype block bone substitutes are widely used in clinical practice.

Materials and Methods: This study enrolled 12 patients who underwent implant placement with GBR in the mandibular anterior region between September 2016 and May 2021 in the Department of Periodontology, Daejeon Dental Hospital, Wonkwang University. GBR was performed using demineralized porcine bone mineral with $10 \%$ collagen (DPBM-C; LegoGraft ${ }^{\mathbb{B}}$ ) and a resorbable collagen membrane (Bio-Gide ${ }^{\circledR}$ or Ossix Plus ${ }^{\circledR}$ ). The surgical site was sutured with 4-0 e-PTFE $\left(\right.$ Biote $\left.^{\circledR}\right)$ and 5-0 nylon (Monosof ${ }^{\mathbb{B}}$ ) by using modified horizontal mattress and interrupted suture methods. Stitch-out was performed two weeks after the operation, and reentry surgery was performed within four to six months after the implant surgery.

Results: There was a significant decrease in bone thickness after five months of implant surgery with GBR compared with the decrease immediately after surgery. However, bone gains of more than $15 \mathrm{~mm}$ were observed at all measurement sites compared with those at baseline.

Conclusion: GBR performed using demineralized porcine bone mineral with $10 \%$ collagen in combination with a resorbable collagen membrane is an effective and favorable treatment modality for peri-implant dehiscence defects in terms of clinical and radiographic outcomes during the healing period.

Keywords: Bone regeneration, Bone substitute, Cone-beam computed tomography, Dental implants, Wound healing 


\section{Introduction}

A dental implant is one of the most useful treatment modalities for the replacement of missing teeth. ${ }^{1}$ A long-term retrospective study showed that the cumulative survival rates of implants in the lower posterior region and anterior teeth were $91.4 \%$ and $94.7 \%$, respectively. ${ }^{2}$ Simonis et al. ${ }^{3}$ reported that the cumulative survival and success rates of long-term implants of 10 to 16 years was $82.94 \%$. A recent systematic review and meta-analysis also confirmed that the 10-year survival rate at the implant level was $96.4 \%$ (95\% confidence interval: $95.2 \%-97.5 \%){ }^{4}$

Guided bone regeneration (GBR) is the most documented and commonly used approach for the augmentation of horizontal and vertical alveolar bone defects in the maxilla and mandible. ${ }^{5}$ Narrow diameter implants are frequently used in the mandibular anterior region because of anatomical constraints (such as limited buccal-oral dimensions), and GBR is often used for appropriate bone augmentation and adequate esthetic outcomes. ${ }^{6,7}$ In esthetically sensitive areas, GBR has the potential to reestablish the buccal and palatal/lingual contours of the alveolar ridge, thus helping the development of soft tissue around the implant. ${ }^{8}$

Although various bone grafting materials are currently used for GBR, data on the superiority of specific biomaterials are controversial. Moreover, achieving reliable and efficient bone augmentation remains challenging. Recently developed soft-type block bone substitutes are widely used in clinical practice, particularly in alveolar ridge preservation procedures. ${ }^{9,10}$ However, relatively few studies have focused on the clinical benefits of using soft-type block bone substitutes for peri-implant dehiscence defects. This study aimed to evaluate the clinical outcomes of porcine-derived, soft-type block bone substitutes in combination with a resorbable collagen membrane for the treatment of peri-implant dehiscence defects in the mandibular anterior region.

\section{II . Materials and Methods}

\section{Patients and ethical statements}

The study protocol was approved by the Institutional Review Board of Daejeon Dental Hospital, Wonkwang University (approval no. W2105/001-001). The requirement for informed consent of all subjects was waived because of the retrospective nature of this study. This study enrolled 12 patients who underwent implant placement with GBR in the mandibular anterior region between September 2016 and May 2021 in the Department of Periodontology, Daejeon Dental Hospital, Wonkwang University. 


\section{Surgical procedure}

A periodontist (JHL) performed all implant surgeries. Antibiotic (netilmicin $50 \mathrm{mg} / 2 \mathrm{~mL}$ ) and analgesic (diclofenac $90 \mathrm{mg} / 2 \mathrm{~mL}$ ) injections were administered to all subjects 30 min before implant surgery, and a course of antibiotic (amoxicillin $500 \mathrm{mg}$ tid for five days) and analgesic (ibuprofen 200 $\mathrm{mg}$ tid for five days) therapy and antimicrobial mouthwash rinse $(0.12 \%$ chlorhexidine, bid for two

\begin{tabular}{|c|c|c|c|c|}
\hline $\begin{array}{l}\text { Screening \& } \\
\text { enrollment }\end{array}$ & $\begin{array}{c}\text { Implantation \& } \\
\text { Bone augmentation }\end{array}$ & $\begin{array}{c}\text { Postoperative } \\
\text { visit }\end{array}$ & $\begin{array}{l}\text { Re-entry } \\
\text { surgery }\end{array}$ & $\begin{array}{l}\text { Final } \\
\text { prosthesis }\end{array}$ \\
\hline & & & & \\
\hline TO & T1 & & T2 & \\
\hline - СBCT & - СВСТ & - Clinical evaluation & - СВСТ & \\
\hline
\end{tabular}
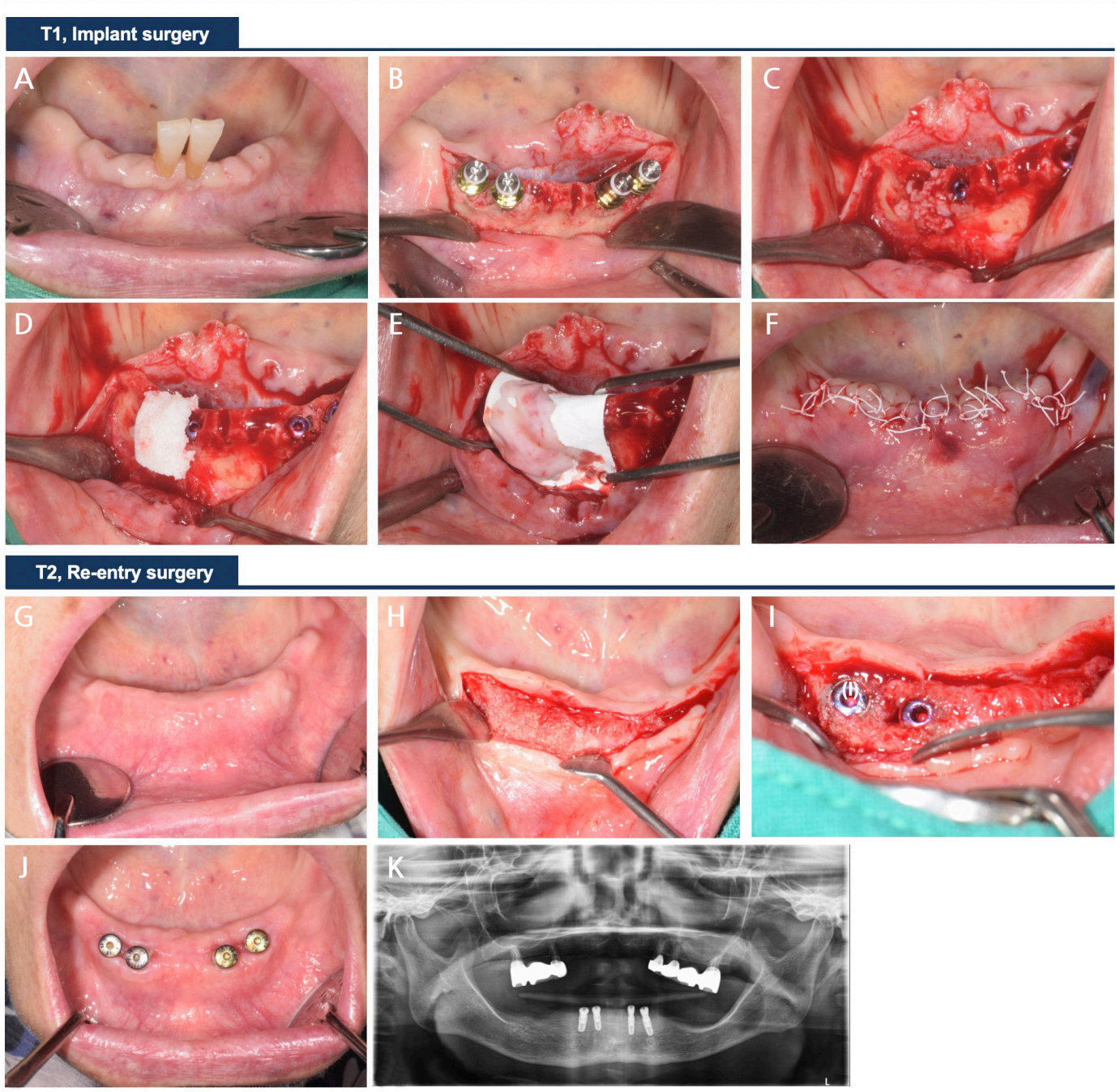

Fig. 1. Schematic presentation of the treatment sequence and time points. (A-F) After dental implant placement, bone augmentation was performed with porcine-derived block bone substitutes and a resorbable collagen membrane. The flap was repositioned and sutured with primary closure, (G-I) At reentry, most of the peri-implant dehiscence defects were resolved, ( $\mathrm{J}$ and $\mathrm{K}$ ) Clinical and radiographic views after surgery. 
weeks; Hexamedine, Bukwang, Seoul, Korea) were prescribed after the implant surgery. A local anesthetic (2\% lidocaine $\mathrm{HCl}$ with 1:100000 epinephrine; Yuhan, Seoul, Korea) was delivered at each surgical site. A mid-crestal incision with or without a vertical releasing incision was made using blades \#12 and \#15. After full-thickness buccal flap elevation, an implant fixture (TSIII ${ }^{\circledR}$; Osstem Implant Co., Seoul, South Korea; Superline ${ }^{\circledR}$; Dentium, Seoul, Korea) was placed with adequate primary stability. After implant placement, GBR was performed using demineralized porcine bone mineral with 10\% collagen (DPBM-C, LegoGraft ${ }^{\circledR}$; Purgo, Seoul, Korea) and a resorbable collagen membrane (BioGide $^{\circledR}$; Geistlich Pharma AG, Wolhusen, Switzerland, or Ossix Plus ${ }^{\circledR}$; Datum Dental Biotech, Telrad, Israel). The surgical site was sutured with 4-0 e-PTFE (Biotex ${ }^{\circledR}$; Purgo Biologics, Seongnam, South Korea) and 5-0 nylon (Monosof ${ }^{\circledR}$; Covidien, Dublin, Ireland) by using the modified horizontal mattress and interrupted suture methods. Stitch-out was performed two weeks after the operation, and reentry surgery was performed within four to six months after the implant surgery (Fig. 1).

\section{Radiographic evaluation}

All subjects underwent cone-beam computed tomography immediately after implant placement (T1) and before reentry surgery (T2). Furthermore, the horizontal bone thickness was measured at the implant fixture shoulder (HW0) and apically at 2 (HW2) and $4 \mathrm{~mm}$ (HW4). Vertical bone thickness (VT) was measured along the long axis of the implant fixture from the implant shoulder to the most coronal level. The oblique bone thickness (45-VT) was measured at an angle of $45^{\circ}$, which divided the long axis and the perpendicular line drawn to this long axis (Fig. 2A). All radiographic parameters were assessed by a single calibrated examiner (JHL; intra-class correlation coefficient $>0.80) .{ }^{11}$
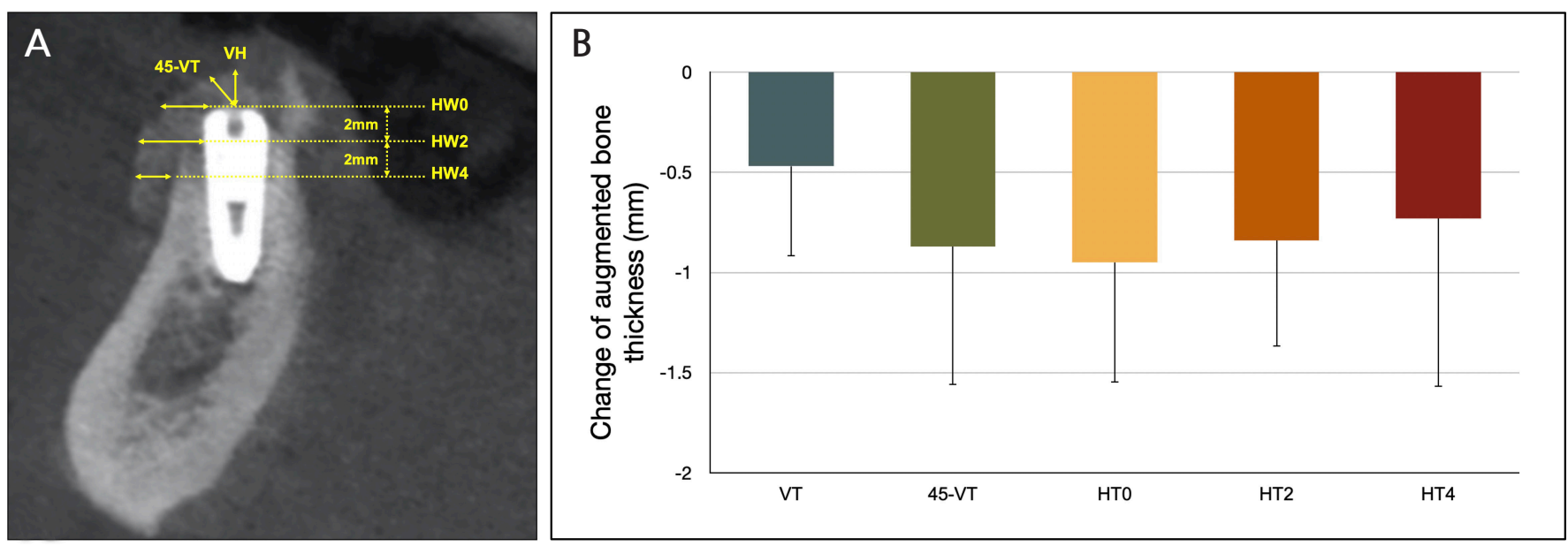

Fig. 2. Schematic diagram of radiographic outcome measurement. (A) Sagittal cone-beam computed tomography reconstruction with the measurements of the augmented site. (B) Mean changes in horizontal and vertical thickness measurements during the healing period. 


\section{Self-reported questionnaire and clinical examination}

The severity of subjective pain and swelling during the two weeks after implant surgery was evaluated using a visual analog scale (VAS) (transformed to a 0-10 scale). The duration of subjective pain and swelling was also assessed using a self-reported questionnaire. Early wound healing parameters, including wound dehiscence and membrane exposure, were evaluated by a single examiner (JHL) during the clinical examination. ${ }^{12}$

\section{Statistical analysis}

All clinical and radiographic outcomes were expressed as frequencies, proportions, means, standard deviations, medians, and first and third quartiles. The Shapiro-Wilk test was used to test for data normality, and the Wilcoxon signed rank test was used to determine the significance of the differences between T1 and T2. All calculations were performed using statistical software (Medcalc version 20.009; Mariakerke, Belgium), and $p<.05$ was considered statistically significant.

\section{Results}

\section{Baseline characteristics}

A total of 12 patients ( 6 women and 6 men; mean age: $62.8 \pm 8.9$ years; age range: $51-81$ years) with 20 surgical sites underwent implant surgery combined with GBR. Table 1 show a summary of the detailed characteristics of the patients and peri-implant dehiscence defects.

\section{Radiographic outcomes}

The vertical and horizontal augmented bone thickness in T1 was $2.17 \pm 0.81 \mathrm{~mm}$ at VT, $3.39 \pm 0.80$ $\mathrm{mm}$ at $45-\mathrm{VT}, 3.34 \pm 0.83 \mathrm{~mm}$ at HT0, $3.35 \pm 0.92 \mathrm{~mm}$ at HT2, and $2.55 \pm 1.14 \mathrm{~mm}$ at HT4; the corresponding thickness in T2 was $1.70 \pm 0.73 \mathrm{~mm}$ at VT, $1.89 \pm 0.76 \mathrm{~mm}$ at $45-\mathrm{VT}, 1.98 \pm 0.72 \mathrm{~mm}$ at HT0, $1.89 \pm 0.85 \mathrm{~mm}$ at HT2, and $1.39 \pm 0.71 \mathrm{~mm}$ at HT4. There were significant differences between all time points $(p<.05)$ (Table 2). The changes in vertical and horizontal bone thickness in T1-T2 was $-0.47 \pm 0.45 \mathrm{~mm}$ at VT, $-0.87 \pm 0.69 \mathrm{~mm}$ at $45-\mathrm{VT},-0.95 \pm 0.60 \mathrm{~mm}$ at $\mathrm{HT},-0.84 \pm 0.53 \mathrm{~mm}$ at $\mathrm{HT} 2$, and $-0.73 \pm 0.84 \mathrm{~mm}$ at HT4 (Fig. 2B).

\section{Postoperative discomfort and wound healing outcomes}

The severity of pain and swelling was $3.3 \pm 2.5$ and $3.9 \pm 2.7$ on the VAS, respectively, and the duration of pain and swelling was $3.7 \pm 2.1$ days and $6.1 \pm 1.2$ days, respectively. Among the enrolled 
Table 1. Baseline characteristics of patients and peri-implant dehiscence defects for 12 enrolled patients and 20 surgical sites

\begin{tabular}{|c|c|c|c|c|c|c|c|}
\hline Patient ID & Sex & $\begin{array}{l}\text { Age } \\
\text { (years) }\end{array}$ & $\begin{array}{l}\text { Tooth } \\
\text { position }\end{array}$ & $\begin{array}{l}\text { Diameter } \\
(\mathrm{mm})\end{array}$ & $\begin{array}{l}\text { Length } \\
(\mathrm{mm})\end{array}$ & $\begin{array}{l}\text { Defect width } \\
\text { (mm) }\end{array}$ & $\begin{array}{l}\text { Defect height } \\
\text { (mm) }\end{array}$ \\
\hline \multirow[t]{2}{*}{1} & \multirow[t]{2}{*}{ M } & \multirow[t]{2}{*}{54} & $\# 31$ & 3.0 & 10.0 & 1.2 & 1.1 \\
\hline & & & $\# 41$ & 3.0 & 10.0 & 2.5 & 1.4 \\
\hline 2 & M & 56 & $\# 32$ & 3.6 & 10.0 & 4.2 & 3.6 \\
\hline \multirow[t]{2}{*}{3} & \multirow[t]{2}{*}{ M } & \multirow[t]{2}{*}{60} & $\# 32$ & 3.5 & 10.0 & 2.3 & 1.2 \\
\hline & & & $\# 42$ & 3.5 & 10.0 & 3.1 & 3.1 \\
\hline 4 & $\mathrm{~F}$ & 69 & $\# 41$ & 3.5 & 8.5 & 1.7 & 3.2 \\
\hline 5 & M & 51 & $\# 32$ & 3.0 & 10.0 & 1.3 & 2.4 \\
\hline 6 & $\mathrm{~F}$ & 66 & $\# 42$ & 4.0 & 11.5 & 2.7 & 3.2 \\
\hline 7 & $\mathrm{~F}$ & 65 & $\# 32$ & 3.5 & 10.0 & 4.1 & 3.9 \\
\hline 8 & M & 81 & $\# 32$ & 3.5 & 8.5 & 3.3 & 2.2 \\
\hline \multirow[t]{4}{*}{9} & \multirow[t]{4}{*}{$\mathrm{F}$} & \multirow[t]{4}{*}{53} & $\# 32$ & 3.5 & 10.0 & 1.9 & 3.3 \\
\hline & & & $\# 33$ & 3.5 & 10.0 & 1.0 & 2.2 \\
\hline & & & $\# 42$ & 3.5 & 10.0 & 0.5 & 0.5 \\
\hline & & & $\# 43$ & 3.5 & 10.0 & 0.5 & 0.5 \\
\hline 10 & M & 62 & $\# 41$ & 3.5 & 8.5 & 1.1 & 1.2 \\
\hline \multirow[t]{4}{*}{11} & \multirow[t]{4}{*}{$\mathrm{F}$} & \multirow[t]{4}{*}{74} & $\# 32$ & 3.5 & 8.5 & 1.2 & 1.7 \\
\hline & & & $\# 33$ & 3.5 & 8.5 & 0.5 & 0.5 \\
\hline & & & $\# 42$ & 3.5 & 8.5 & 2.6 & 3.5 \\
\hline & & & $\# 43$ & 3.5 & 8.5 & 1.8 & 2.8 \\
\hline 12 & $\mathrm{~F}$ & 63 & $\# 32$ & 3.0 & 10.0 & 1.2 & 1.2 \\
\hline
\end{tabular}

Defect width: measured as the linear distance between the widest left and right points of the dehiscence defect, defect height: measured as the linear distance from the top of the implant shoulder to the initial bone-to-implant contact at the dehiscence defect.

Table 2. Changes in augmented bone thickness after GBR procedure of peri-implant dehiscence defects

\begin{tabular}{rccc} 
& T1 & T2 & $p$-values \\
VT $(\mathrm{mm})$ & $2.17 \pm 0.81$ & $1.70 \pm 0.73$ & $<.001$ \\
& {$[2.15,(1.85,2.79)]$} & {$[1.72,(1.17,1.99)]$} & \\
45-VT $(\mathrm{mm})$ & $3.39 \pm 0.80$ & $1.89 \pm 0.76$ & $<.001$ \\
& {$[3.45,(3.14,3.94)]$} & {$[2.12,(1.22,2.42)]$} & $<.001$ \\
HT0 $(\mathrm{mm})$ & $3.34 \pm 0.83$ & $1.98 \pm 0.72$ & $<.001$ \\
& {$[3.38,(3.00,4.05)]$} & {$[2.19,(1.46,2.47)]$} & \\
HT2 $(\mathrm{mm})$ & $3.35 \pm 0.92$ & $1.89 \pm 0.85$ & .001 \\
& {$[3.39,(2.89,4.23)]$} & {$[2.00,(1.43,2.29)]$} & \\
\hline
\end{tabular}

Data are expressed as mean \pm standard deviation [median, (first and third quartiles)].

HT0, HT2, and HT4: Horizontal thickness at 0,2 , and $4 \mathrm{~mm}$ apically below the coronal end of the implant fixture.

VT and 45-VT: Vertical thickness measured along the long axis of the coronal end of the implant fixture and $45^{\circ}$ vertical thickness at an angle of $45^{\circ}$ relative to the long axis of the coronal end of the implant fixture.

$p$-values were calculated using the Wilcoxon signed rank test. 


\section{Table 3. Early wound healing outcomes}

\begin{tabular}{ll} 
Pain & \\
Severity (VAS) & $3.3 \pm 2.5$ \\
Duration (days) & $3.7 \pm 2.1$ \\
Swelling & \\
\hline Severity (VAS) & $3.9 \pm 2.7$ \\
Duration (days) & $6.1 \pm 1.2$ \\
Wound dehiscence and membrane exposure & \\
No & $15(75.0 \%)$ \\
Yes & $5(25.0 \%)$ \\
\hline
\end{tabular}

Data are expressed as mean \pm SD.

VAS, visual analog scale.

patients, wound dehiscence and membrane exposure occurred at five surgical sites $\left(25.0 \%\right.$; Bio-Gide ${ }^{\circledR}$; $\mathrm{n}=2$ and Ossix Plus ${ }^{\circledR} ; \mathrm{n}=3$ ) (Table 3).

\section{IV . Discussion}

For predictive and successful GBR outcomes, space creation and maintenance are the major factors required to achieve sufficient bone regeneration. ${ }^{13}$ Although particulated xenogenic bone substitutes in combination with resorbable collagen membranes have been routinely used for GBR, these biomaterials are less efficient in providing space and stabilizing the wound. ${ }^{14}$ A number of different biomaterials (including pin, tenting screw, and titanium-reinforced membrane or mesh) have been proposed to prevent the collapse of the augmented area around the peri-implant dehiscence defects. However, the specific biomaterials that offer the best clinical outcomes are still unclear. ${ }^{15,16}$

Several studies have shown that the tight closure of a wound with sutures causes the significant loss of bone grafting materials, particularly the pronounced displacement in the occlusal-buccal space of the implant fixture shoulder. ${ }^{17,18}$ Recent in vitro cone-beam computed tomographic studies have compared the dimensional stability between particulated and block bone substitutes in combination with resorbable collagen membranes for the GBR of peri-implant defects. ${ }^{19}$ These studies show that there is significant displacement of the particulated demineralized bovine bone mineral (DBBM) during flap closure, which results in a partial collapse of the occlusal-buccal space. However, block-type DBBM exhibited less collapse than particulated DBBM. The amount of membrane collapse at the implant shoulder level was reduced by more than $50 \%$ (from -1.1 to $-0.5 \mathrm{~mm}$ ) when block-type DBBM was used instead of particulated DBBM. 
A recent study evaluated the augmentation stability of GBR in peri-implant dehiscence defects and reported that the change at HT0 and VT of the DBBM-C group (HT0: $-0.68 \pm 0.53 \mathrm{~mm}[-21.0 \%]$; VT: $-0.91 \pm 0.73 \mathrm{~mm}[-30.1 \%])$ was significantly more stable and persistent than that of particulated DBBM group (HT0: $-1.30 \pm 0.77 \mathrm{~mm}[-40.4 \%]$; VT: $-1.57 \pm 0.67 \mathrm{~mm}[-52.0] ; p<.05){ }^{20}{ }^{2}$ These results were consistent with those of the current study.

The study outcomes showed that there was a significant decrease in bone thickness after five months of implant surgery with GBR compared with the decrease immediately after surgery. However, bone gains of more than $1.5 \mathrm{~mm}$ were observed at all measurement sites compared with those at baseline.

Within the limitations of this study, only cases using DPBM-C could be included, and a direct comparison with particulated DPBM or DBBM-C could not be achieved. In addition, retrospective and short-term studies have inherent limitations. Further studies, including controlled clinical trials with long-term follow-up periods, are required.

\section{Conclusion}

GBR with DPBM-C in combination with resorbable collagen membrane is an effective and favorable treatment modality for peri-implant dehiscence defects in terms of clinical and radiographic outcomes during the healing period.

\section{References}

1. Quirynen M, Herrera D, Teughels W, Sanz M. Implant therapy: 40 years of experience. Periodontol 2000 2014;66:7-12.

2. Balshi TJ, Wolfinger GJ, Stein BE, Balshi SF. A long-term retrospective analysis of survival rates of implants in the mandible. Int J Oral Maxillofac Implants 2015;30:1348-54.

3. Simonis P, Dufour T, Tenenbaum H. Long-term implant survival and success: a 10-16-year followup of non-submerged dental implants. Clin Oral Implants Res 2010;21:772-7.

4. Howe MS, Keys W, Richards D. Long-term (10-year) dental implant survival: A systematic review and sensitivity meta-analysis. J Dent 2019;84:9-21.

5. Elgali I, Omar O, Dahlin C, Thomsen P. Guided bone regeneration: materials and biological mechanisms revisited. Eur J Oral Sci 2017;125:315-37.

6. Cordaro L, Torsello F, Mirisola Di Torresanto V, Rossini C. Retrospective evaluation of mandibular incisor replacement with narrow neck implants. Clin Oral Implants Res 2006;17:730-5.

7. Temmerman A, Keestra JA, Coucke W, Teughels W, Quirynen M. The outcome of oral implants placed in bone with limited bucco-oral dimensions: a 3-year follow-up study. J Clin Periodontol 2015;42:311-8. 
8. Benic GI, Thoma DS, Munoz F, Sanz Martin I, Jung RE, Hammerle CH. Guided bone regeneration of peri-implant defects with particulated and block xenogenic bone substitutes. Clin Oral Implants Res 2016;27:567-76.

9. Lee JH, Kim DH, Jeong SN. Comparative assessment of anterior maxillary alveolar ridge preservation with and without adjunctive use of enamel matrix derivative: A randomized clinical trial. Clin Oral Implants Res 2020;31:1-9.

10. Lee JH, Jeong SN. Effect of enamel matrix derivative on alveolar ridge preservation in the posterior maxilla: A randomized controlled clinical trial. Clin Implant Dent Relat Res 2020;22:622-30.

11. Koo TK, Li MY. A Guideline of Selecting and Reporting Intraclass Correlation Coefficients for Reliability Research. J Chiropr Med 2016;15:155-63.

12. Lee JH, Park YS, Kim YT, Kim DH, Jeong SN. Assessment of early discomfort and wound healing outcomes after periodontal surgery with and without enamel matrix derivative: an observational retrospective case-control study. Clin Oral Investig 2020;24:229-37.

13. Wang HL, Boyapati L. "PASS" principles for predictable bone regeneration. Implant Dent 2006;15:817.

14. Benic GI, Thoma DS, Jung RE, Sanz-Martin I, Unger S, Cantalapiedra A, et al. Guided bone regeneration with particulate vs. block xenogenic bone substitutes: a pilot cone beam computed tomographic investigation. Clin Oral Implants Res 2017;28:e262-e70.

15. Rakhmatia YD, Ayukawa Y, Furuhashi A, Koyano K. Current barrier membranes: titanium mesh and other membranes for guided bone regeneration in dental applications. J Prosthodont Res 2013;57:3-14.

16. Benic GI, Hammerle $\mathrm{CH}$. Horizontal bone augmentation by means of guided bone regeneration. Periodontol 2000 2014;66:13-40.

17. Mertens C, Braun S, Krisam J, Hoffmann J. The influence of wound closure on graft stability: An in vitro comparison of different bone grafting techniques for the treatment of one-wall horizontal bone defects. Clin Implant Dent Relat Res 2019;21:284-91.

18. Urban IA, Lozada JL, Wessing B, Suarez-Lopez del Amo F, Wang HL. Vertical Bone Grafting and Periosteal Vertical Mattress Suture for the Fixation of Resorbable Membranes and Stabilization of Particulate Grafts in Horizontal Guided Bone Regeneration to Achieve More Predictable Results: A Technical Report. Int J Periodontics Restorative Dent 2016;36:153-9.

19. Mir-Mari J, Wui H, Jung RE, Hammerle CH, Benic GI. Influence of blinded wound closure on the volume stability of different GBR materials: an in vitro cone-beam computed tomographic examination. Clin Oral Implants Res 2016;27:258-65.

20. Jung EH, Jeong SN, Lee JH. Augmentation stability and early wound healing outcomes of guided bone regeneration in peri-implant dehiscence defects with L- and I-shaped soft block bone substitutes: A clinical and radiographic study. Clin Oral Implants Res 2021;32:1308-17. 